\title{
Diagnosing Septate Uterus Using Three- Dimensional Ultrasound Using Three Different Classifications: An Interobserver and Intraobserver Agreement Study
}

\section{Diagnóstico de útero septado com ecografia tridimensional usando três classificações diferentes: Um estudo de concordância interobservador $e$ intraobservador}

\author{
Carla Peixoto $^{1,2(0)}$ Maite Castro ${ }^{3(0)}$ Isabel Carriles ${ }^{4}$ \\ Juan Luis Alcazar ${ }^{4}{ }^{\circ}$

\footnotetext{
${ }^{1}$ Department of Obstetrics and Gynecology, Centro Hospitalar São João, Porto, Portugal

2 Faculty of Medicine, University of Porto, Porto, Portugal

${ }^{3}$ Centro de Infertilidad y Reproduccion Humana, Barcelona, Spain

${ }^{4}$ Department of Obstetrics and Gynecology, Clínica Universidad de

Navarra, University of Navarra, Pamplona, Spain

${ }^{5}$ Department of Obstetrics and Gynecology, University and

Polytechnic Hospital La Fe, Valencia, Spain

6 Department of Obstetrics and Gynecology, University Hospital,

Salamanca, Spain
}

Maria de Arriba ${ }^{5}$ Victoria Lapresa 6 ()

Rev Bras Ginecol Obstet 2021;43(12):911-918.

\author{
Address for correspondence Carla Peixoto, MD, Alameda Prof. \\ Hernâni Monteiro, 4200-319, Porto, Portugal \\ (e-mail: carlapcp@gmail.com).
}

\begin{abstract}
Keywords

- uterus

- ultrasonography

- congenital anomaly

Objective Currently, there are up to three different classifications for diagnosing septate uterus. The interobserver agreement among them has been poorly assessed. Objective To assess the interobserver agreement of nonexpert sonographers for classifying septate uterus using the European Society of Human Reproduction and Embryology/European Society for Gynaecological Endoscopy (ESHRE/ESGE), American Society for Reproductive Medicine (ASRM), and Congenital Uterine Malformations by Experts (CUME) classifications.

Methods A total of 50 three-dimensional (3D) volumes of a nonconsecutive series of women with suspected uterine malformation were used. Two nonexpert examiners evaluated a single 3D volume of the uterus of each woman, blinded to each other. The following measurements were performed: indentation depth, indentation angle, uterine fundal wall thickness, external fundal indentation, and indentation-to-wallthickness (I:WT) ratio. Each observer had to assign a diagnosis in each case, according
\end{abstract}

received

August 7, 2020

accepted

October 13, 2021
DOI https://doi.org/

10.1055/s-0041-1740271. ISSN 0100-7203. (c) 2021. Federação Brasileira de Ginecologia e Obstetrícia. All rights reserved.

This is an open access article published by Thieme under the terms of the Creative Commons Attribution License, permitting unrestricted use, distribution, and reproduction so long as the original work is properly cited. (https://creativecommons.org/licenses/by/4.0/)

Thieme Revinter Publicações Ltda., Rua do Matoso 170, Rio de Janeiro, RJ, CEP 20270-135, Brazil 


\section{Resumo}

\author{
Palavras-chave \\ - útero \\ - ecografia \\ - anomalia congênita
}

to the three classification systems (ESHRE/ESGE, ASRM, and CUME). The interobserver agreement regarding the ESHRE/ESGE, ASRM, and CUME classifications was assessed using the Cohen weighted kappa index (k). Agreement regarding the three classifications (ASRM versus ESHRE/ESGE, ASRM versus CUME, ESHRE/ESGE versus CUME) was also assessed.

Results The interobserver agreement between the 2 nonexpert examiners was good for the ESHRE/ESGE ( $k=0.74 ; 95 \%$ confidence interval [Cl]: 0.55-0.92) and very good for the ASRM and CUME classification systems $(\mathrm{k}=0.95 ; 95 \% \mathrm{Cl}: 0.86-1.00$; and $\mathrm{k}=0.91$; 95\%Cl: $0.79-1.00$, respectively). Agreement between the ESHRE/ESGE and ASRM classifications was moderate for both examiners. Agreement between the ESHRE/ESGE and CUME classifications was moderate for examiner 1 and good for examiner 2. Agreement between the ASRM and CUME classifications was good for both examiners.

Conclusion The three classifications have good (ESHRE/ESGE) or very good (ASRM and CUME) interobserver agreement. Agreement between the ASRM and CUME classifications was higher than that for the ESHRE/ESGE and ASRM and ESHRE/ESGE and CUME classifications.

Objetivo Atualmente, existem até três classificações diferentes para o diagnóstico de útero septado. A concordância interobservador entre eles tem sido pouco avaliada.

Objetivo Avaliar a concordância interobservador de ecografistas não especialistas para classificar úteros septados usando as classificações European Society of Human Reproduction and Embryology/European Society for Gynaecological Endoscopy (ESHRE/ESGE, na sigla em inglês), American Society for Reproductive Medicine (ASRM, na sigla em inglês) e Congenital Uterine Malformations by Experts (CUME, na sigla em inglês).

Métodos Foram utilizados 50 volumes tridimensionais (3D) de uma série não consecutiva de mulheres com suspeita de malformação uterina. Dois examinadores não especialistas avaliaram um único volume 3D do útero de cada mulher, mutuamente cegos. As seguintes medidas foram aferidas: profundidade de indentação, ângulo de indentação, espessura da parede do fundo uterino, indentação externa do fundo e relação entre indentação e a espessura da parede (I:WT, na sigla em inglês). Cada observador teve que atribuir um diagnóstico em cada caso, de acordo com os três sistemas de classificação (ESHRE/ESGE, ASRM e CUME). A concordância interobservador em relação às classificações ESHRE/ESGE, ASRM e CUME foi avaliada usando o índice kappa ponderado de Cohen (k). A concordância em relação às três classificações (ASRM versus ESHRE/ESGE, ASRM versus CUME e ESHRE/ ESGE versus (UME) também foi avaliada.

Resultados A concordância interobservador entre os 2 examinadores não especialistas foi boa para a classificação ESHRE/ESGE ( $k=0,74$, intervalo de confiança [IC] 95\%: $0,55-0,92)$ e muito boa para os sistemas de classificação ASRM e CUME ( $k=0,95$; IC 95\%: 0,86-1,00; e $k=0,91 ;$ IC95\%: 0,79-1,00, respectivamente). A concordância entre as classificações ESHRE/ESGE e ASRM foi moderada para ambos os examinadores. A concordância entre as classificações ESHRE/ESGE e CUME foi moderada para o examinador 1 e boa para o examinador 2. A concordância entre as classificações ASRM e CUME foi boa para ambos os examinadores.

Conclusão As três classificações apresentam concordância interobservador boa (ESHRE/ESGE) ou muito boa (ASRM e CUME). A concordância entre as classificações ASRM e CUME foi maior do que entre as classificações ESHRE/ESGE e ASRM e ESHRE/ESGE e CUME. 


\section{Introduction}

Congenital uterine malformations were described for the first time in 1800s and, since then, several classification systems have been developed for describing different types of uterine and cervical/vaginal anomalies, ${ }^{1}$ whose incidence has been reported as of between 0.2 and $0.4 \%$ in the general population and of between 3 and $13 \%$ in infertile patients. ${ }^{2-7}$

Classically, septate uterus has been associated with poor reproductive and obstetric outcomes, and surgical metroplasty is advocated in these cases, with the aim of improving these outcomes. ${ }^{8-11}$ Notwithstanding, evidence that this surgery is beneficial is rather arguable. ${ }^{12}$ Differently from septate uterus, arcuate/normal and bicornuate uteri do not require surgery. ${ }^{8-11}$ However, from the beginning, there was some difficulty in the classification of uterine malformations, mainly due to the discrepancy between the diagnostic criteria and the diagnostic techniques used. ${ }^{13}$ To overcome these limitations, three-dimensional (3D) ultrasound has been proposed as the gold standard technique to classify uterine malformations, as it seems to be better to evaluate the level of distortion of the uterine fundus, and also to reduce the interobserver variability. ${ }^{14,15}$

The European Society of Human Reproduction and Embryology/European Society for Gynaecological Endoscopy (ESHRE/ESGE) and the American Society for Reproductive Medicine (ASRM) have both published their recommendations on how to classify uterine anomalies, using the coronal plane of the uterus. The ESHRE/ESGE classification suggests using an indentation-to-wall-thickness (I:WT) ratio $>50 \%$ for diagnosing a septate uterus and an external fundal indentation $>50 \%$ to diagnose a bicornuate uterus. ${ }^{13,16}$ The ASRM classification considers a uterus as septate when there is both an indentation depth $>15 \mathrm{~mm}$ and an indentation angle $<90^{\circ}$; a normal/arcuate uterus when there is both an indentation depth $<10 \mathrm{~mm}$ and an indentation angle $>90^{\circ}$; and a bicornuate uterus when the external fundal indentation is $>10 \mathrm{~mm}$. According to this classification, some cases could not be classified as septate or not-septate (falling in the so-called gray zone). ${ }^{8}$ Although both classifications have very objective criteria, they do not coincide, which means that a high percentage of uteri classified as septate by the ESHRE/ESGE classification are classified as arcuate/normal by the ASRM classification. ${ }^{17-20}$ More recently, a group of experts (Congenital Uterine Malformations by Experts [CUME]) proposed new criteria for diagnosing a septate uterus: indentation depth $\geq$ $10 \mathrm{~mm}$, indentation angle $<140^{\circ}$, and $\mathrm{I}: \mathrm{WT}>110 \%{ }^{18}$

The main objective of the present study was to assess the interobserver agreement of nonexpert sonographers in classifying septate uteri using the ESHRE/ESGE, ASRM, and CUME classifications in each case. Secondly, we also aimed to compare the agreement for each examiner for diagnosing septate uterus between the three different classifications (ESHRE/ESGE, ASRM, and CUME).

\section{Methods}

The present study was a single-center retrospective analysis of patients with suspicion of congenital uterine malforma- tion who underwent transvaginal ultrasound at the Department of Obstetrics and Gynecology of the Clínica Universidad de Navarra, Pamplona, Spain. Due to the study design and to the anonymization of the 3D volumes, formal approval by the Institutional Review Board from the Clínica Universidad de Navarra was waived. However, all women had given oral informed consent to acquire and use their 3D datasets for the present research. The present study was performed at the Clínica Universidad de Navarra between September and October 2018.

The inclusion criterion was: women with suspected uterine malformation in infertility setting who underwent 3D uterine evaluation. The exclusion criteria were: diagnosis of bicornuate or didelfis uterus or poor-quality 3D volume.

An expert examiner (Alcazar J. L.) randomly selected cases from the hospital database. Two nonexpert examiners (Peixoto $\mathrm{C}$. and Castro $\mathrm{M}$ ) evaluated a single 3D volume of the uterus of each woman. All 3D datasets had been acquired by one expert examiner (Alcazar J. L.) using either a Voluson 730 Expert or Voluson E8 machines (GE Healthcare, Chicago, IL, USA).

The nonexpert examiners had basic training on ultrasound in gynecology, with no special focus on uterine malformations, but both were undergoing a training program for ultrasound assessment of congenital uterine anomalies. Before the study, the nonexpert examiners took a short (2 hours) theoretical training session focused on the ESHRE/ESGE, ASRM and CUME classifications. Additionally, they read the original papers in which the criteria to classify uterine malformations were described. ${ }^{8,13,18}$ They were also trained to use the 4D View Ultrasound software (GE Healthcare, Chicago, IL, USA).

The two observers manipulated the uterine 3D volumes, blinded to each other. After obtaining the coronal plane and using the Volume Contrast Imaging (VCI) function according to the CUME recommendations, ${ }^{18}$ they performed the following measurements: indentation depth, indentation angle, uterine fundal wall thickness, external fundal indentation, and I:WT ratio. Each observer had to assign a diagnosis (normal/arcuate, septate) in each case, according to the three classification systems (ESHRE/ESGE, ASRM, and CUME) (-Fig. 1).

Arbitrarily, to avoid cases from falling in the grey zone, we decided the following: for the ASRM classification, in case that only one criterion was present, the case was considered as normal. For the CUME classification, the uterus was considered as septate if at least two criteria were present.

The examiners were also instructed not to discuss their impressions among themselves or with the expert after the assessment. We did not set a maximum time for performing evaluations of the 3D volumes.

The interobserver agreement between the two nonexpert examiners regarding the ESHRE/ESGE, ASRM, and CUME classifications was assessed using the Cohen weighted kappa index (k) with 95\% confidence intervals (CIs) and percentage of agreement. ${ }^{21}$ 
A

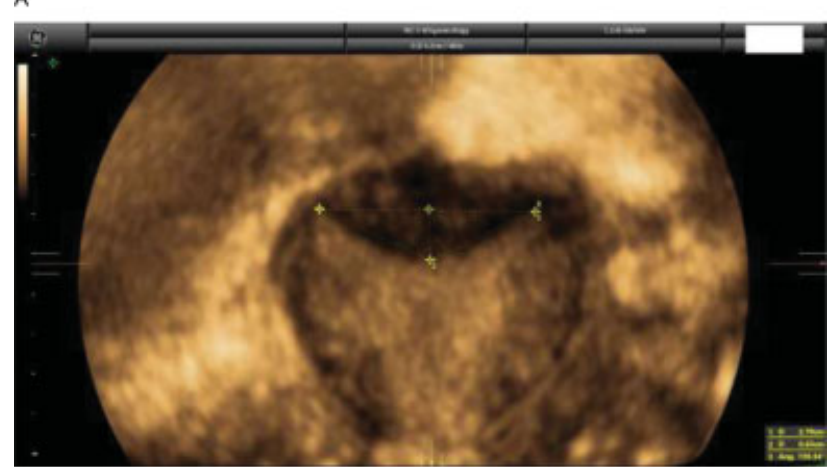

B

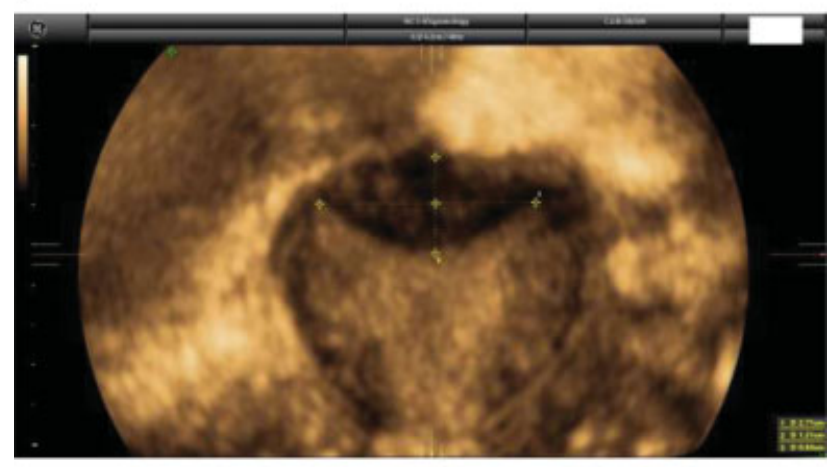

C

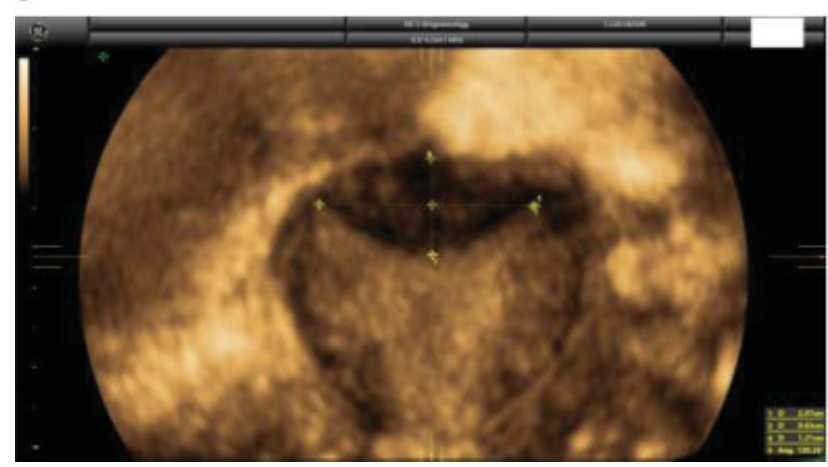

Fig. 1 A case of a septate uterus according to the ESHRE/ESGE classification (I:WT $=52 \%)(A)$, but normal/arcuate according to the ASRM (indentation: $0.63 \mathrm{~cm}$, angle: $130^{\circ}$ ) (B) and to the CUME (indentation: $0.63 \mathrm{~cm}$, angle: $130^{\circ}, \mathrm{I}: \mathrm{WT}$ : $52 \%$ ) classifications (C).

We also assessed the interobserver agreement for the two nonexpert examiners regarding the three classifications (ASRM versus ESHRE/ESGE, ASRM versus CUME, and ESHRE/ESGE versus CUME).
The kappa value was interpreted regarding the reporting of the reliability/strength of agreement as follows: poor $<0.20$; fair $=0.21$ to 0.40 ; moderate $=0.41$ to $0.60 ; \operatorname{good}=0.61$ to 0.80 ; and very $\operatorname{good}=0.81$ to $1.00 .^{22}$

Statistical calculations were done using GraphPad software (GraphPad Software, Inc., San Diego, CA, USA). Sample size calculation was not performed.

\section{Results}

Forty-seven 3D volumes of women were included in the present study. This number was chosen arbitrarily. The interobserver agreement between the two nonexpert examiners for classifying uterine malformations is shown in - Tables 1, 2 and 3. Overall, it was good for the ESHRE/ ESGE $(\mathrm{k}=0.74 ;$ 95\%CI: 0.55-0.92) classification (-Table 1 ) and very good for the ASRM and CUME classifications $(\mathrm{k}=0.96$; $95 \% \mathrm{CI}: 0.88-1.00$; and $\mathrm{k}=0.91$; $95 \% \mathrm{CI}: 0.79$ 1.00 , respectively) (-Tables 2 and $\mathbf{3}$ ).

The agreement between the different classifications systems is shown in - Tables $\mathbf{4 , 5 , 6 , 7 , 8 , 9}$. When comparing the agreement for classifying uterine anomalies between the ESHRE/ESGE and ASRM classifications, we observed that it was moderate for both examiners (- Tables 4 and $\mathbf{5}$ ). We also observed that 14 cases were classified as septate by the ESHRE/ESGE classification and as normal/arcuate by the ASRM classification by both examiners. For both examiners, 9 of these cases were classified as normal/arcuate (64.3\%) and 5 as septate (35.7\%) when using the CUME classification.

The agreement between the ESHRE/ESGE and CUME classifications was moderate for examiner 1 and good for examiner 2 (-Tables 6 and 7). Finally, the agreement between the ASRM and CUME classifications was good for both examiners (-Tables 8 and $\mathbf{9}$ ).

\section{Discussion}

As far as we know, this is the first study to assess the interobserver agreement of the three existing classification systems to describe normal, arcuate, and septate uterus. We have shown that the evaluation of $3 \mathrm{D}$ volumes of uteri is reproducible among nonexpert examiners.

Table 1 Interobserver agreement for nonexpert examiners for classifying uterine congenital anomalies using the ESHRE/ESGE classification

\begin{tabular}{lllllll}
\hline ESHRE/ESGE & \multicolumn{7}{c}{ Examiner 1 } \\
\hline Examiner 2 & Normal/arcuate & Septate & Bicornuate & $\begin{array}{l}\text { Weighted Kappa } \\
(95 \% \mathrm{Cl})\end{array}$ & $\begin{array}{l}\text { Agreement } \\
(\%)\end{array}$ \\
& Normal/arcuate & 16 & 3 & - & 0.74 & $86 \%$ \\
& Septate & 3 & 25 & - & $(0.55-0.92)$ & \\
& Bicornuate & - & 1 & 2 & & \\
\hline
\end{tabular}

Abbreviations: $\mathrm{Cl}$, confidence interval; ESHRE, European Society of Human Reproduction and Embryology; ESGE, European Society for Gynaecological Endoscopy. 
Table 2 Interobserver agreement for nonexpert examiners for classifying uterine congenital anomalies using the ASRM classification

\begin{tabular}{|c|c|c|c|c|c|c|}
\hline \multicolumn{7}{|l|}{ ASRM } \\
\hline & & \multicolumn{5}{|l|}{ Examiner 1} \\
\hline \multirow[t]{4}{*}{ Examiner 2} & & Normal/arcuate & Septate & Bicornuate & $\begin{array}{l}\text { Weighted Kappa } \\
(95 \% \mathrm{Cl})\end{array}$ & $\begin{array}{l}\text { Agreement } \\
(\%)\end{array}$ \\
\hline & Normal/arcuate & 33 & - & - & \multirow{3}{*}{$\begin{array}{l}0.96 \\
(0.88-1.00)\end{array}$} & \multirow[t]{3}{*}{$98 \%$} \\
\hline & Septate & - & 15 & - & & \\
\hline & Bicornuate & - & 1 & 1 & & \\
\hline
\end{tabular}

Abbreviations: $\mathrm{Cl}$, confidence interval; ASRM, American Society for Reproductive Medicine.

Table 3 Interobserver agreement for nonexpert examiners for classifying uterine congenital anomalies using the CUME classification

\begin{tabular}{|c|c|c|c|c|c|}
\hline \multicolumn{6}{|l|}{ CUME } \\
\hline & & \multicolumn{4}{|l|}{ Examiner 1} \\
\hline \multirow[t]{3}{*}{ Examiner 2} & & Normal/arcuate & Septate & $\begin{array}{l}\text { Kappa } \\
(95 \% \mathrm{Cl})\end{array}$ & $\begin{array}{l}\text { Agreement } \\
(\%)\end{array}$ \\
\hline & Normal/arcuate & 27 & 1 & \multirow{2}{*}{$\begin{array}{l}0.91 \\
(0.79-1.00)\end{array}$} & \multirow[t]{2}{*}{$96 \%$} \\
\hline & Septate & 1 & 18 & & \\
\hline
\end{tabular}

Abbreviations: $\mathrm{Cl}$, confidence interval; CUME, Congenital Uterine Malformations by Experts.

Table 4 Intraobserver agreement for examiner 1 when using the ASRM and the ESHRE/ESGE classifications

\begin{tabular}{|c|c|c|c|c|c|c|}
\hline \multicolumn{7}{|l|}{ Examiner 1} \\
\hline & & ASRM & & & & \\
\hline \multirow[t]{4}{*}{ ESHRE/ESGE } & & Normal/arcuate & Septate & Bicornuate & $\begin{array}{l}\text { Weighted Kappa } \\
(95 \% \text { CI) }\end{array}$ & $\begin{array}{l}\text { Agreement } \\
(\%)\end{array}$ \\
\hline & Normal/arcuate & 19 & - & - & \multirow{3}{*}{$\begin{array}{l}0.48 \\
(0.28-0.68)\end{array}$} & \multirow[t]{3}{*}{$70 \%$} \\
\hline & Septate & 14 & 14 & - & & \\
\hline & Bicornuate & - & 1 & 2 & & \\
\hline
\end{tabular}

Abbreviations: ASRM, American Society for Reproductive Medicine; Cl, confidence interval; ESHRE, European Society of Human Reproduction and Embryology; ESGE, European Society for Gynaecological Endoscopy.

Table 5 Intraobserver agreement for examiner 2 when using the ASRM and the ESHRE/ESGE classifications

\begin{tabular}{|c|c|c|c|c|c|c|}
\hline \multicolumn{7}{|l|}{ Examiner 2} \\
\hline & & ASRM & & & & \\
\hline \multirow[t]{4}{*}{ ESHRE/ESGE } & & Normal/arcuate & Septate & Bicornuate & $\begin{array}{l}\text { Weighted Kappa } \\
(95 \% \mathrm{Cl})\end{array}$ & $\begin{array}{l}\text { Agreement } \\
(\%)\end{array}$ \\
\hline & Normal/arcuate & 19 & - & - & \multirow{3}{*}{$\begin{array}{l}0.47 \\
(0.27-0.67)\end{array}$} & \multirow[t]{3}{*}{$70 \%$} \\
\hline & Septate & 14 & 15 & - & & \\
\hline & Bicornuate & - & 1 & 1 & & \\
\hline
\end{tabular}

Abbreviations: ASRM, American Society for Reproductive Medicine; Cl, confidence interval; ESHRE, European Society of Human Reproduction and Embryology; ESGE, European Society for Gynaecological Endoscopy.

The agreement between observers is higher when using the ASRM and CUME classifications. Actually, our data confirm the results previously reported by Ludwin et al., ${ }^{20}$ who showed that the ASRM classification was better than the
ESHRE/ESGE classification for diagnosing septate uterus. In addition, we have also shown that the criteria used by the new classification system (CUME), despite being apparently more complex, are highly reproducible among examiners 
Table 6 Intraobserver agreement for examiner 1 when using the CUME and the ESHRE/ESGE classifications

\begin{tabular}{|c|c|c|c|c|c|}
\hline \multicolumn{6}{|c|}{ Examiner 1} \\
\hline & & ESHRE/ESGE & & & \\
\hline \multirow[t]{3}{*}{ CUME } & & Normal/arcuate & Septate & $\begin{array}{l}\text { Карра } \\
(95 \% C I)\end{array}$ & $\begin{array}{l}\text { Agreement } \\
\text { (\%) }\end{array}$ \\
\hline & Normal/arcuate & 18 & 10 & \multirow{2}{*}{$\begin{array}{l}0.59 \\
(0.39-0.80)\end{array}$} & \multirow[t]{2}{*}{$79 \%$} \\
\hline & Septate & - & 19 & & \\
\hline
\end{tabular}

Abbreviations: Cl, confidence interval; CUME, Congenital Uterine Malformations by Experts; ESHRE, European Society of Human Reproduction and Embryology; ESGE, European Society for Gynaecological Endoscopy.

Table 7 Intraobserver agreement for examiner 2 when using the CUME and the ESHRE/ESGE classifications

\begin{tabular}{llllll}
\hline Examiner 2 & & & & & \\
\hline & ESHRE/ESGE & & & \\
\hline CUME & Normal/arcuate & Septate & $\begin{array}{l}\text { Kappa } \\
(95 \% \mathrm{Cl})\end{array}$ & $\begin{array}{l}\text { Agreement } \\
(\%)\end{array}$ \\
& & & & 0.63 & $81 \%$ \\
& Normal/arcuate & 19 & 9 & $(0.43-0.83)$ & \\
\hline
\end{tabular}

Abbreviations: Cl, confidence interval; CUME, Congenital Uterine Malformations by Experts; ESHRE, European Society of Human Reproduction and Embryology; ESGE, European Society for Gynaecological Endoscopy.

Table 8 Intraobserver agreement for examiner 1 when using the CUME and the ASRM classifications

\begin{tabular}{llllll}
\hline Examiner 1 & & & & \\
\hline & ASRM & & \\
\hline CUME & Normal/arcuate & Septate & $\begin{array}{l}\text { Kappa } \\
(95 \% \mathrm{Cl})\end{array}$ & $\begin{array}{l}\text { Agreement } \\
(\%)\end{array}$ \\
& Normal/arcuate & 28 & & 0.77 & $89 \%$ \\
& Septate & 5 & 14 & $(0.58-0.96)$ & \\
\hline
\end{tabular}

Abbreviations: ASRM, American Society for Reproductive Medicine; $\mathrm{Cl}$, confidence interval. CUME, Congenital Uterine Malformations by Experts.

Table 9 Intraobserver agreement for examiner 2 when using the CUME and the ASRM classifications

\begin{tabular}{|c|c|c|c|c|c|}
\hline \multicolumn{6}{|c|}{ Examiner 2} \\
\hline & & \multicolumn{4}{|l|}{ ASRM } \\
\hline \multirow[t]{3}{*}{ CUME } & & Normal/arcuate & Septate & $\begin{array}{l}\text { Kappa } \\
(95 \% \mathrm{Cl})\end{array}$ & $\begin{array}{l}\text { Agreement } \\
\text { (\%) }\end{array}$ \\
\hline & Normal/arcuate & 28 & - & \multirow{2}{*}{$\begin{array}{l}0.77 \\
(0.58-0.96)\end{array}$} & \multirow[t]{2}{*}{$89 \%$} \\
\hline & Septate & 5 & 14 & & \\
\hline
\end{tabular}

Abbreviations: ASRM, American Society for Reproductive Medicine; $\mathrm{Cl}$, confidence interval; CUME, Congenital Uterine Malformations by Experts.

$(\mathrm{k}=0.91)$. This is an important finding, given that this new classification has not yet been validated after its publication.

In our study, the agreement between the ESHRE/ESGE and ASRM criteria was moderate. This finding is in line with those of previous studies ${ }^{18,20}$ and raises concern regarding the use of the ESHRE/ESGE classification, since its use could lead to an overdiagnosis of septate uterus and to a potential increase of surgical corrections. ${ }^{17}$ This is relevant since recent evidence suggests no benefit in obstetrical outcomes with surgery. ${ }^{23}$ Our data also support the results published by the CUME group, ${ }^{18}$ given that we demonstrated that, in comparison with CUME criteria, the ESHRE/ESGE classification overestimates the number of septate uteri. Overall, the agreement between the CUME and the ESHRE/ESGE and the ASRM classifications was good, but it was slightly better between the CUME and ASRM classifications than between the CUME and ESHRE/ESGE classifications.

An interesting question is related to the fact that if the ESHRE/ESGE classification would use the I:I+WT ratio, instead of the I:WT ratio, the rate of septate uterus would be similar to CUME classification. 
The strengths of the present study are its design and the use of an optimal diagnostic method (3D ultrasonography) for diagnosing uterine anomalies. ${ }^{6,24}$ The participation of nonexpert examiners could be seen as a potential strength, since it allows the evaluation of the reproducibility of the different classifications in "everyday practice."

However, certainly, our study design can be also considered as a limitation, since the sources of variability regarding the real-time ultrasound and 3D volume acquisition were not taken to account, since the two observers have used previously acquired 3D datasets, which may overestimate the reproducibility of the measurements.

As stated above, our study has limitations. One limitation of the present study is that the examiners had to manipulate the 3D volumes by rotation in all 3 orthogonal planes. This manipulation has an inherent variability between observers, ${ }^{18,20}$ as the same uterus might provide different images depending on the angle at which the coronal plane is obtained. Other possible limitations of the present study are the small number of cases analyzed and the high quality of 3D volumes, which may have contributed to a lower number of "discrepant" cases. One final limitation that must be mentioned is that we arbitrarily decided to assume that there were no gray-zone cases, since the uteri were classified as septate only when both criteria of the ASRM classification or at least two criteria of the CUME classification were present. It is clear that this point could bias the results, since, somehow, we forced providing a diagnosis in all cases, which is not true in the case of the ASRM classification.

Despite these limitations, we consider that our findings may have clinical relevance and should prompt further studies to determine which classification should be used.

\section{Conclusion}

In general, the three classifications have good (ESHRE/ESGE) or very good (ASRM, CUME) interobserver agreement, which makes them all good methods to classify congenital uterine anomalies. However, agreement between the ASRM and the CUME classifications was higher than that for the ESHREESGE and the ASRM and for the ESHRE/ESGE and the CUME classifications.

\section{Conflict of interests}

The authors have no conflict of interests to declare.

\section{References}

1 Doerr W. [Jean Cruveilhier, Carl v. Rokitansky, Rudolf Virchow. Fundamente der Pathologie, Gedanken aus Anlass der hundersten Jährung von Rokitanskys Todestag]. Virchows Arch A Pathol Anat Histol. 1978;378(01):1-16. Doi: 10.1007/BF00427181 German.

2 Nahum GG. Uterine anomalies. How common are they, and what is their distribution among subtypes? J Reprod Med. 1998;43(10): 877-887

3 Chan YY, Jayaprakasan K, Zamora J, Thornton JG, Raine-Fenning N, Coomarasamy A. The prevalence of congenital uterine anomalies in unselected and high-risk populations: a systematic review. Hum Reprod Update. 2011;17(06):761-771. Doi: 10.1093/ humupd/dmr028

4 Byrne J, Nussbaum-Blask A, Taylor WS, Rubin A, Hill M, O'Donnell $\mathrm{R}$, et al. Prevalence of Müllerian duct anomalies detected at ultrasound. Am J Med Genet. 2000;94(01):9-12. Doi: 10.1002/1096-8628(20000904)94:1<9:aid-ajmg3>3.0.co;2-h

5 Acién P. Incidence of Müllerian defects in fertile and infertile women. Hum Reprod. 1997;12(07):1372-1376. Doi: 10.1093/ oxfordjournals.humrep.a019588

6 Saravelos SH, Cocksedge KA, Li TC. Prevalence and diagnosis of congenital uterine anomalies in women with reproductive failure: a critical appraisal. Hum Reprod Update. 2008;14(05): 415-429. Doi: 10.1093/humupd/dmn018

7 Oppelt P, von Have M, Paulsen M, Strissel PL, Strick R, Brucker S, et al. Female genital malformations and their associated abnormalities. Fertil Steril. 2007;87(02):335-342. Doi: 10.1016/j.fertnstert.2006.07.1501

8 Practice Committee of the American Society for Reproductive Medicine. Electronic address: ASRM@asrm.org Practice Committee of the American Society for Reproductive Medicine. Uterine septum: a guideline. Fertil Steril. 2016;106(03):530-540. Doi: 10.1016/j.fertnstert.2016.05.014

9 Valle RF, Ekpo GE. Hysteroscopic metroplasty for the septate uterus: review and meta-analysis. J Minim Invasive Gynecol. 2013;20(01):22-42. Doi: 10.1016/j.jmig.2012.09.010

10 Kowalik CR, Goddijn M, Emanuel MH, Bongers MY, Spinder T, de Kruif JH, et al. Metroplasty versus expectant management for women with recurrent miscarriage and a septate uterus. Cochrane Database Syst Rev. 2011;(06):CD008576. Doi: 10.1002/14651858.CD008576.pub3

11 Rikken JF, Kowalik CR, Emanuel MH, Mol BWJ, Van der Veen F, van Wely M, et al. Septum resection for women of reproductive age with a septate uterus. Cochrane Database Syst Rev. 2017;1(01): CD008576. Doi: 10.1002/14651858.CD008576.pub4

12 Rikken JFW, Verhorstert KWJ, Emanuel MH, Bongers MY, Spinder $\mathrm{T}$, Kuchenbecker WKH, et al. Septum resection in women with a septate uterus: a cohort study. Hum Reprod. 2020;35(07):1578-1588. Doi: 10.1093/humrep/dez284

13 Grimbizis GF, Di Spiezio Sardo A, Saravelos SH, Gordts S, Exacoustos C, Van Schoubroek D, et al. The Thessaloniki ESHRE/ESGE consensus on diagnosis of female genital anomalies. Hum Reprod. 2016;31(01):2-7. Doi: 10.1093/humrep/dev264

14 Salim R, Woelfer B, Backos M, Regan L, Jurkovic D. Reproducibility of three-dimensional ultrasound diagnosis of congenital uterine anomalies. Ultrasound Obstet Gynecol. 2003;21(06):578-582. Doi: $10.1002 /$ uog. 127

15 Ludwin A, Ludwin I, Banas T, Knafel A, Miedzyblocki M, Basta A. Diagnostic accuracy of sonohysterography, hysterosalpingography and diagnostic hysteroscopy in diagnosis of arcuate, septate and bicornuate uterus. J Obstet Gynaecol Res. 2011;37(03): 178-186. Doi: 10.1111/j.1447-0756.2010.01304.x

16 Grimbizis GF, Gordts S, Di Spiezio Sardo A, Brukcer S, De Angelis C, Gergolet M, et al. The ESHRE/ESGE consensus on the classification of female genital tract congenital anomalies. Hum Reprod. 2013; 28(08):2032-2044. Doi: 10.1093/humrep/det098

17 Knez J, Saridogan E, Van Den Bosch T, Mavrelos D, Ambler G, Jurkovic D. ESHRE/ESGE female genital tract anomalies classification system-the potential impact of discarding arcuate uterus on clinical practice. Hum Reprod. 2018;33(04):600-606. Doi: 10.1093/humrep/dey043

18 Ludwin A, Martins WP, Nastri CO, Ludwin I, Coelho Neto MA, Leitão VM, et al. Congenital Uterine Malformation by Experts (CUME): better criteria for distinguishing between normal/arcuate and septate uterus? Ultrasound Obstet Gynecol. 2018;51(01):101-109. Doi: 10.1002/uog.18923

19 Ludwin A, Ludwin I. Comparison of the ESHRE-ESGE and ASRM classifications of Müllerian duct anomalies in everyday practice. 
918 Diagnosing Septate Uterus Using Three-Dimensional Ultrasound Peixoto et al.

Hum Reprod. 2015;30(03):569-580. Doi: 10.1093/humrep/deu344

20 Ludwin A, Ludwin I, Kudla M, Kottner J. Reliability of the European Society of Human Reproduction and Embryology/European Society for Gynaecological Endoscopy and American Society for Reproductive Medicine classification systems for congenital uterine anomalies detected using three-dimensional ultrasonography. Fertil Steril. 2015;104(03):688-97.e8. Doi: 10.1016/j. fertnstert.2015.06.019

21 Kundel HL, Polansky M. Measurement of observer agreement. Radiology. 2003;228(02):303-308. Doi: 10.1148/radiol.2282011860
22 Brennan P, Silman A. Statistical methods for assessing observer variability in clinical measures. BMJ. 1992;304(6840):1491-1494. Doi: 10.1136/bmj.304.6840.1491

23 National Institute for Health and Care Excellence (NICE) Hysteroscopic metroplasty of a uterine septum for recurrent miscarriage: interventional procedures guidance. Lyon: NICE; 2015

24 Berger A, Batzer F, Lev-Toaff A, Berry-Roberts C. Diagnostic imaging modalities for Müllerian anomalies: the case for a new gold standard. J Minim Invasive Gynecol. 2014;21(03):335-345. Doi: 10.1016/j.jmig.2013.10.014 